Original Research Article

\title{
Patterns of adverse drug reactions: a study in a tertiary care
}

\author{
Donepudi Pavan Kumar*
}

Department of Pharmacology, NRI Medical College, Guntur, Andhra Pradesh, India

Received: 27 April 2019

Accepted: 02 May 2019

\section{*Correspondence to:}

Dr. Donepudi Pavan Kumar, Email: pavandonepudi@ yahoo.com

Copyright: (c) the author(s), publisher and licensee Medip Academy. This is an openaccess article distributed under the terms of the Creative Commons Attribution NonCommercial License, which permits unrestricted noncommercial use, distribution, and reproduction in any medium, provided the original work is properly cited.

\begin{abstract}
Background: Adverse drug reaction, usually reported by pharmacovigilance, either through health care professionals or the patients themselves is of utmost importance to give an accurate estimate of the severity of the drug and also if the ADRs are casual, preventable or severe.

Methods: A total of 42 patients satisfied the WHO definition of 'adverse drug reactions' were included in the study. The demographic details were taken, and the regular physical examination and clinical examination was done for all the patients. The latest drug they were on and the dosage were analyzed and the type of reaction was assessed. The causality, severity and preventability were also assessed.

Results: Majority of the ADRs were found in the medicine department, followed pulmonology, obstetrics-gynecology and paediatrics. B-lactams were the major cause of ADRs with $42.2 \%$, followed by NSAIDs with $23.8 \%$, fluoroquinolones with $19 \%$ and $9.5 \%$ due to antitubercular drugs. $66.7 \%$ of the ADRs were mild, $28.6 \%$ were moderate and $4.8 \%$ were severe. The most common type of ADR were skin rashes $(40.5 \%)$, urticara $(16.7 \%)$, headaches $(26.2 \%)$, insomnia $(21.4 \%)$, diarrhoea $(21.4 \%)$, abdominal pain $(14.3 \%)$ and vomiting $(4.8 \%)$. Most of the ADRs were evaluated as probably preventable (69\%), definitely preventable $(26.2 \%)$, non preventable $(4.8 \%)$.

Conclusions: Most of the drug reactions are mild and preventable. More health care professionals as well as patients need to be aware of the drug reactions at much early age so as to prevent the condition before it becomes serious.
\end{abstract}

Keywords: Adverse drug reactions, Causality, Pharmacovigilance, Preventability, Tertiary care centre

\section{INTRODUCTION}

One of the main unavoidable risk factor in the use of drug therapy is the adverse reactions to the drugs. ${ }^{1}$ It is therefore one of the major concerns in medicine. It has been described by the World Health Organization as a "noxious, unintended and undesired effect of a drug, which occur at doses used in humans for prophylaxis, diagnosis or cure of a disease." $"$ ADRs are common, at times can be life threatening and in general leads to increased expenses. This is the reason that the clinicians are requested to be aware of the reactions that can be caused by the drugs before prescribing them. ${ }^{3}$

ADRs are common in the hospital setup. They have been classified into two types, one that is the cause of hospitalization and the other which occurs after hospitalization. It is estimated that $5 \%$ of the hospitalizations and one in $10-20 \%$ of the hospitalized patients are due to drug reactions. ${ }^{4}$ In 1994, it was suggested by Lazarou J et al, that 10000 deaths in US had occurred due to ADRs, although this was considered to be 
biased and inflated data. ${ }^{5,6}$ Consequently a few studies were conducted wherein the data accumulated was small, and thus the documentation of the ADRs was minimal. In India, ADRs are said to occur in $1.8 \%$ to $25.1 \%$ of the population, with $8 \%$ of them leading to hospitalization. About $50 \%$ of the commonly used drugs result in adverse reactions, which was not detected prior to approval. ${ }^{7,8}$

Pharmacovigilance relates to the activities concerning the detection, assessment, understanding and prevention of these adverse drug reactions. ${ }^{2}$ Although the field of science is developing by leaps and bounds, there is a lot of underreporting of the ADRs that takes place, thus giving a wrong picture. It is important for the clinicians to be aware of the toxicity of the prescribing drugs and be vigilant of the reactions that can occur. Proper information is useful to identify and minimize, if possible, the preventable ADRs, thus ensuring a safe and effective use of the drug. ${ }^{4}$ Therefore reporting of the adverse reaction, may it be through health care professionals or the patients themselves is of utmost importance to give an accurate estimate of the severity of the drug and also if the ADRs are casual, preventable or severe.

In this study, authors tried to study the different types of the adverse reactions among the patients in various outpatient as well as inpatient wards NRI Medical College, Guntur, Andhra Pradesh, India.

\section{METHODS}

This study was conducted by the Department of Pharmacology at NRI Medical College, Guntur, Andhra Pradesh, India from January 2016 to December 2017. This study was conducted on 42 patients, who came to the OP and IP wards of all the Departments such as General Medicine, General Surgery, Pulmonology, Obstetrics and Gynaecology, ENT, Paediatrics and Dermatology. Among all these patients, those who experienced ADRs as per the WHO definition were included into the study. ${ }^{9}$

The demographic details were taken for all the patients and the regular physical examination and clinical examination was done for all of them. The latest drug they were on, the dosage and number of times taken were analysed in detail. The type of reaction was assessed and noted.

The causality of the ADR was assessed as per the Naranjo's probability scale and they were classified according to the Rawlings and Thompson classification i.e. if they were predictable pharmacologically according to their dose or if they were bizarre. ${ }^{10,11}$ Severity of the ADR was seen based in the modified Hartwig and Siegel's scale which classifies the ADRs into mild, moderate an severe. ${ }^{12}$ Preventability of the ADRs were classified into definitely preventable, probably preventable and not preventable based on the modified Shumock GT et al, criteria. ${ }^{13}$

\section{RESULTS}

A total of 42 patients satisfied the WHO definition of 'adverse drug reactions'. ${ }^{1}$ Of them, 22 were females and 20 were males. Most of the cases were between 18 to 60 years of age and were classified as belonging to the adult group of patients. 11 patients were elderly i.e. $>60$ years of age and 7 patients were below 18 years (Table 1 ).

Table: 1: Age and sex distribution of the patients.

\begin{tabular}{|lll|l|}
\hline Age & Male & Female & Total \\
\hline $\begin{array}{l}\text { Adolescent } \\
(<18 \text { yrs })\end{array}$ & 5 & 2 & $7(16.7 \%)$ \\
\hline $\begin{array}{l}\text { Adult } \\
(18-60 \text { yrs })\end{array}$ & 10 & 14 & $24(57.1 \%)$ \\
\hline $\begin{array}{l}\text { Elderly } \\
(>60 \text { yrs })\end{array}$ & 5 & 6 & $11(26.2 \%)$ \\
\hline Total & $20(47.6 \%)$ & $22(52.4 \%)$ & 42 \\
\hline
\end{tabular}

The number of ADRs were distributed based on the department in which they were found. It was observed that the majority of the ADRs were found in the medicine department $(38.1 \%)$. This was followed by $19.04 \%$ in pulmonology department, and $11.9 \%$ each in obstetrics and gynaecology and paediatric departments (Figure 1).

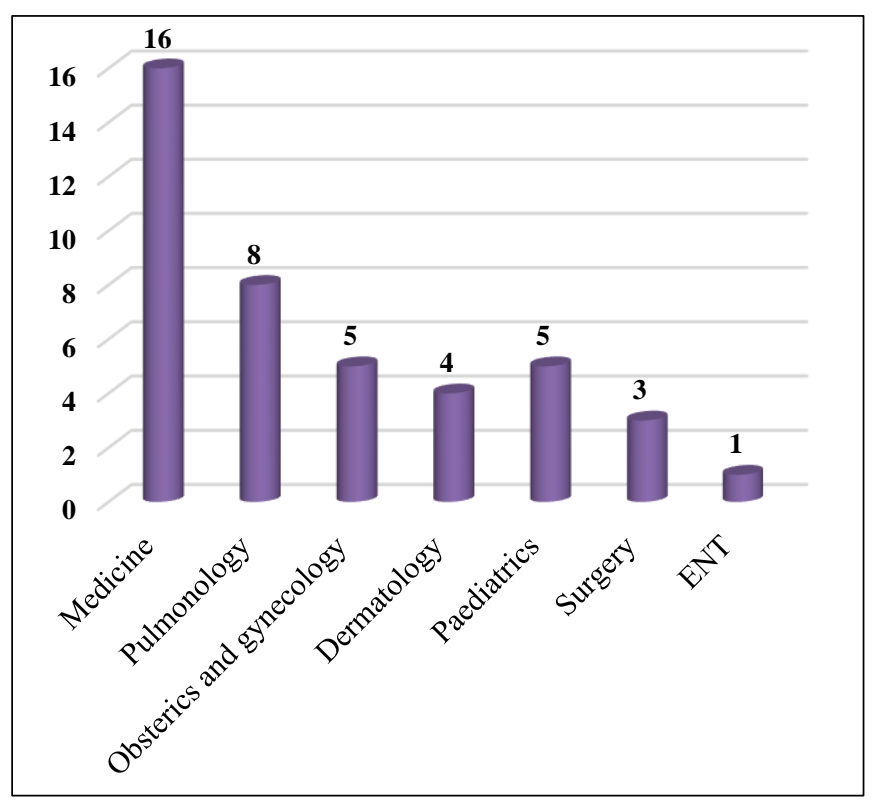

Figure 1: Department wise distribution of ADRs.

Antibiotics like B- lactams were the major cause of ADRs in this study accounting to $42.2 \%$ of the total ADRs, which was followed by NSAIDs with $23.8 \%$. Fluoroquinolones attributed to $19 \%$ of the total ADRs and $9.5 \%$ of the ADRs were due to antitubercular drugs (Table 2).

Most of the ADRs which were observed in the study were mild (66.7\%). $12(28.6 \%)$ were moderate while $2(4.8 \%)$ were severe (Figure 2). 


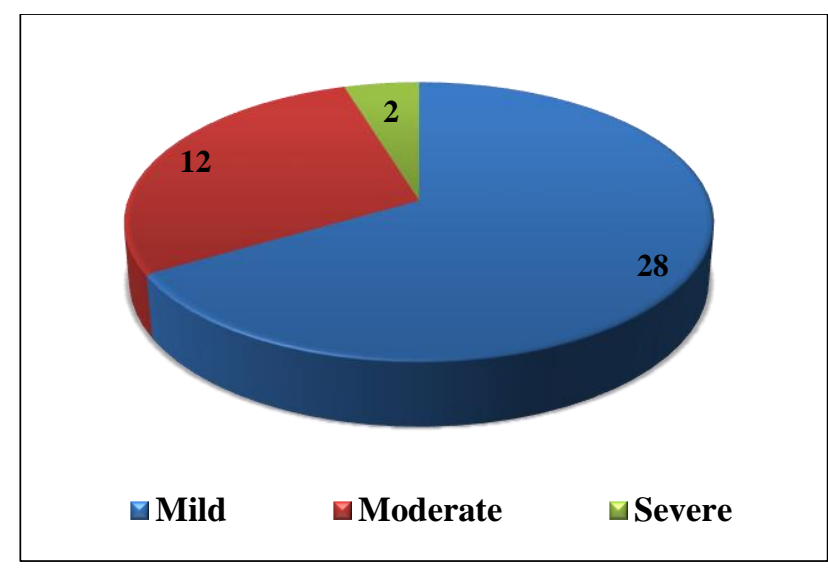

Figure 2: Severity of ADR.

The most common type of ADR were skin rashes in 14 $(40.5 \%)$ of the cases, and urticara in $7(16.7 \%) .11(26.2 \%)$ of the patients complained of headaches and $9(21.4 \%)$ of insomnia. Diarrhoea was observed in $9(21.4 \%)$ of the cases, abdominal pain in $6(14.3 \%)$ and vomiting in 2 (4.8\%) (Figure 3).

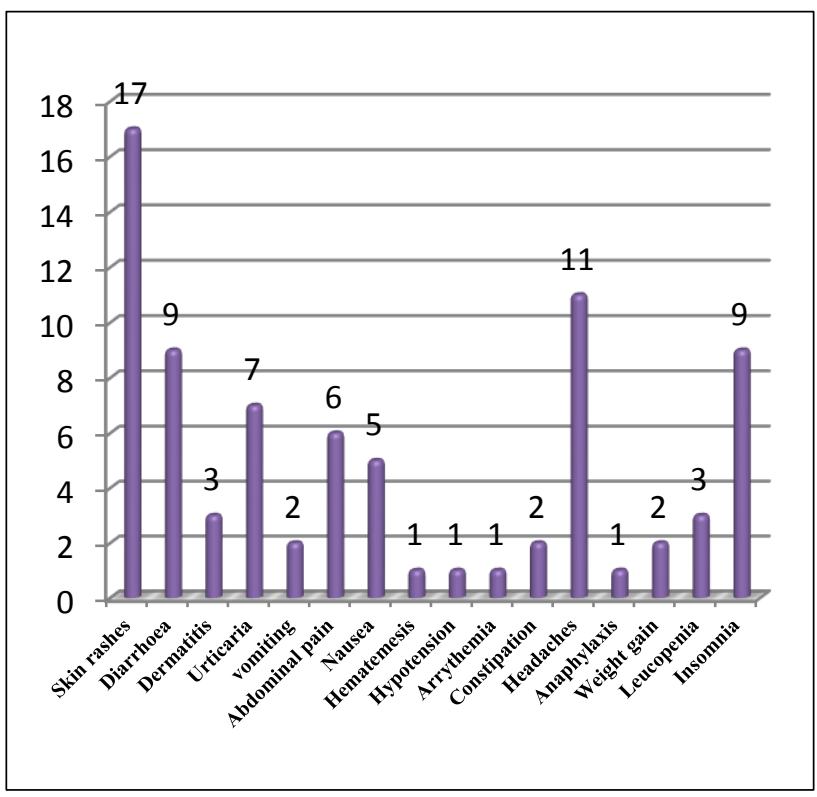

Figure 3: Types of reactions due to ADRs.

Table 2: Drugs reporting to cause ADRs.

\begin{tabular}{|lll|}
\hline Drugs & Number & Percentage \\
\hline B Lactams & 19 & $42.2 \%$ \\
\hline NSAIDS & 10 & $23.8 \%)$ \\
\hline Fluoroquinolones & 8 & $19.0 \%$ \\
\hline Metronidazole & 3 & $7.1 \%$ \\
\hline Carbamezepine & 2 & $4.8 \%$ \\
\hline Fosphenytoin & 1 & $2.4 \%$ \\
\hline Pantoprazole (Inj) & 2 & $4.8 \%$ \\
\hline Antitubercular & 4 & $9.5 \%$ \\
\hline Tramadol & 3 & $7.1 \%$ \\
\hline Brufen & 2 & $4.8 \%$ \\
\hline
\end{tabular}

The causality assessment was done according to Naranjo's probability scale 25 and was found that $21(50 \%)$ were probable, $16(38.1 \%)$ were possible and $4(9.5 \%)$ were certain. None of the ADRs were unlikely, conditional or assessable in our study (Figure 4).

The preventability assessment was based on the modified Shumock and Thornton criteria. Most of the ADRs were evaluated as propably preventable (69\%), followed by 11 $(26.2 \%)$, which were definitely preventable. $2(4.8 \%)$ of them were non preventable (Figure 5).

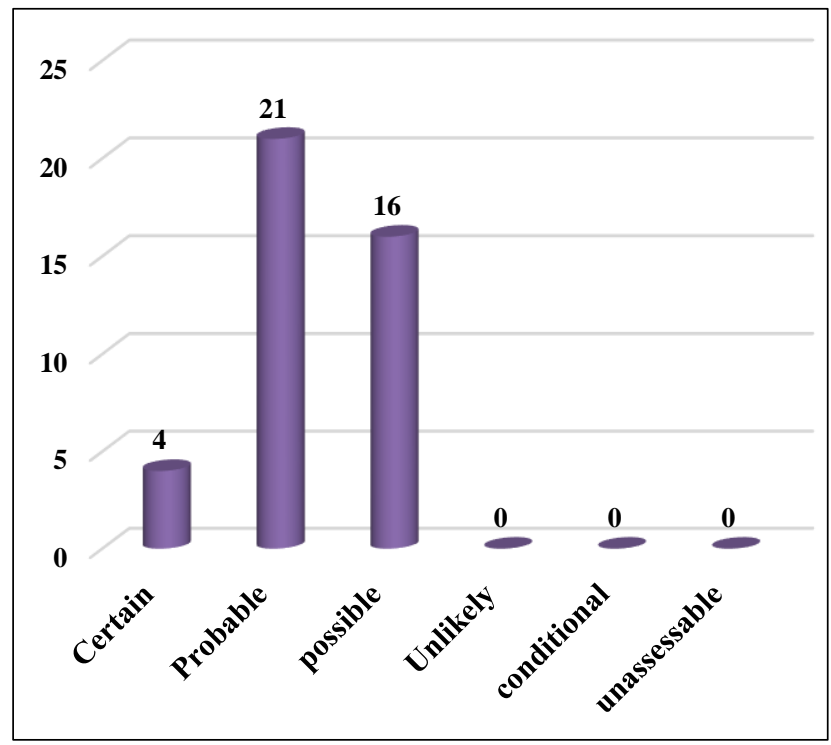

Figure 4: Causality assessment of ADRs.

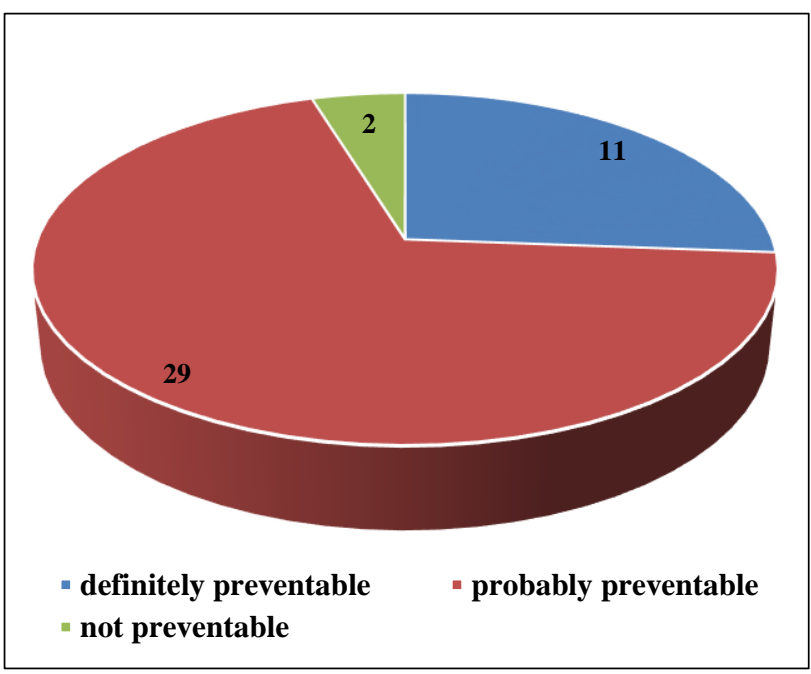

Figure 5: Preventability assessment of ADRs.

\section{DISCUSSION}

India is said to be the second highest market for the sale of prescription drugs in the world, yet only about $2 \%$ of the adverse drug reactions are reported. The main cause for this low figure is the underreporting of the ADRs. Thus, it is imperative that more of the ADRs are reported so that the 
correct picture is attained and we get the real picture of the scenario. This study was conducted to ascertain the number of ADRs in our institute.

The present study included patients who were diagnosed with symptoms of ADRs, thus the prevalence of ADRs in our hospital was not reported. However, a prevalence of $7.59 \%$ by Kumar A et al, $10.2 \%$ by Hurwitz N, $9.2 \%$ by De Vries EN et al, and $6.6 \%$ by Moore $\mathrm{N}$ et al, were reported in their respective studies., ${ }^{44-16}$

In the present study, the number of women $(53.4 \%)$ were slightly higher than that of male population (47.6\%). However, this number was not found to be significant. These results were similar to other studies by Saravanan SS et al, Sutradhar SD et al, and Naranjo et al. ${ }^{17-19}$ In contrast, in a study by Palanisamy S et al, Kumar A et al, Goyal YN et al, Adhikari A et al, the number of males affected by ADRs were more than the females. ${ }^{1,4,20,21}$ Thus, the gender was not found to be a risk factor for the development of ADR. The age group to be more affected was the adult group i.e. between 19 to 60 years. Similar results were observed in studies by Palanisamy S et al, Kumar A et al and Behera SK et al. 1,4,22

It was observed in another study that adult females were more prone to the ADRs as they were ore into polypharmacy and drug intake as well as being more sensitive to medications. ${ }^{23,24}$ Authors, however did not differentiate between the males and the females in this study.

Department of medicine in present study had more number of ADRs. This could be due to the fact that there was more inflow of patients in that department. This was followed by pulmonology department followed by OBGY and paediatrics. ADR in medicine in larger numbers was also observed by Vora MB et al, in his study. ${ }^{25}$ Higher rate of ADRs in medicine was also observed by Behera SK et al. ${ }^{22}$

Of the drugs, b-lactams were the most common cause of ADRs as they were the most common antibiotics prescribed. This was in concurrence with other similar studies by Rodriguez-Pena $\mathrm{R}$ et al, and Raut $\mathrm{A}$ et al. ${ }^{26,27}$ In a similar study by Kumar A et al, antimicrobials was found to be the most common cause of ADRs, followed by NSAIDs and antihypertensive drugs, which was corroborated by studies by Gor AP et al, Karthikeyan M et al, Gupta $A$ et al and Sriram $S$ et al. ${ }^{4,7,28-30}$. In contrast, Behera SK et al, observed antiretroviral drugs to be the most common cause of ADRs. ${ }^{22}$

Most of the ADRs in the study were mild (66.7\%), while $28.6 \%$ were moderate. This was in accordance with a study by Shamna $\mathrm{M}$ et al and Naranjo et al, who also observed $65 \%$ to be mild, $35 \%$ to be moderate and only $3 \%$ to be severe. ${ }^{19,31}$ Other studies showed slightly varied results. About $74.2 \%$ of the cases were moderate in nature in a study by Kumar A et al, $53.7 \%$ were mild in a study by
Arulmani R et al, $80 \%$ were severe reported by Hurwitz N, and $61 \%$ were moderate by Palanisamy $\mathrm{S}$ et al. ${ }^{1,4,14,32}$

In the present study, skin was the most common organ to be affected $(64.3 \%)$ with the predominant symptom being skin rashes seen in $40.5 \%$ of the patients, urticaria in $16.7 \%$, dermatitis in $7.1 \%$. GIT was another prominent site of reactions, with $21.4 \%$ having diarrhea, $14.3 \%$ with abdominal pain and $4.8 \%$ with vomiting. Headaches were observed in $26.2 \%$ of the patients and insomnia in $21.4 \%$. GIT was the most affected site in studies by Kumar A et al, Sriram S et al, Goyal YN et al and Uchit GP et al. ${ }^{4,7,20,33}$ In a study by Naranjo et al, $75 \%$ of the patients had cutaneous reactions. ${ }^{19}$ Similar results were reported by Chawla $\mathrm{S}$ et al, Behera SK et al and Lihite RJ et al. ${ }^{22,34,35}$

Total $50 \%$ of the cases were classified as probable when causality assessment was done while $38.1 \%$ were classified as possible. None of the ADRs were unlikely, conditional or assessable according to the causality assessment. The causality assessment I a study by Kumar A et al showed the most common one was probable ADR in $61.2 \%$ cases, which was slightly more than this study, and possible in $32.3 \%$, slightly lower than this study. ${ }^{4}$

Though authors had no cases of uncertain, their study had $1.5 \% 4$. $62.5 \%$ of reaction were reported as probable in a study by Naranjo et al, $70.22 \%$ in a study by Sutradhar SD et al, and $88.6 \%$ in another study by Mandavi DS et al. ${ }^{18,19,36}$

In this study, according to the preventability assessment, $69 \%$ of the cases were evaluated as probably preventable, $26.2 \%$ as definitely preventable ad $4.8 \%$ as nonpreventable. A higher definitely preventable rate was observed in studies by De Vries EN et al (43.5\%), Palanisamy S et al (40\%) and Sriram S et al (28\%). ${ }^{1,7,15}$

\section{CONCLUSION}

Most of the drug reactions are mild and preventable. But, the information of the knowledge of the severity of the reactions, their preventability and the patient background information are scarce. This study is just a drop in the ocean for attaining such data. More such studies need to be undertaken to increase the data and information of the prevalence of this condition. More health care professionals need to be aware of the drug reactions at much early age so as to prevent the condition before it becomes serious. Moreover, the patients also need to be counseled regarding to the side effects and reactions that the drug can cause so that they can seek help before it worsens.

\author{
Funding: No funding sources \\ Conflict of interest: None declared \\ Ethical approval: The study was approved by the \\ Institutional Ethics Committee
}




\section{REFERENCES}

1. Palanisamy S, Arul Kumaran KSG, Rajasekaran A. A study on assessment, Monitoring, documentation and reporting of adverse drug reactions at a multi-specialty tertiary Care teaching hospital in south India. IJPRIF. 2009;1:1519-22.

2. Ahmad A, Patel I, Balkrishnan R, Mohanta GP, Manna PK. An evaluation of knowledge, attitude and practice of Indian pharmacists towards adverse drug reaction reporting: a pilot study. Persp Clin Res. 2013;4(4):204.

3. Pirmohamed M, Breckenridge AM, Kitteringham NR, Park BK. Adverse drug reactions. BMJ. 1998;316(7140):1295-8.

4. Kumar A, Kansal D, Sharma PK, Bhardwaj A, Sawaraj S. To study the pattern of adverse drug reactions among patients hospitalized in the medical wards of a tertiary care hospital. Int $\mathbf{J}$ Basic Clin Pharmacol. 2016;5:1972-7.

5. Lazarou J, Pomeranz BH, Corey PN. Incidence of adverse drug reactions in hospitalized patients: a metaanalysis of prospective studies. JAMA. 1998;279(15):1200-5.

6. Kvasz M, Allen IE, Gordon MJ, Ro EY, Estok R, Olkin I, et al. Adverse drug reactions in hospitalized patients: a critique of a meta-analysis. Medscape Gen Med. 2000;2(2):E3.

7. Sriram S, Ghasemi A, Ramasamy R, Devi M, Balasubramanian R, Ravi TK, et al. Prevalence of adverse drug reactions at a private tertiary care hospital in South India. J Res Med Sci. 2011;16(1):1625.

8. Rabbur RS, Emmerton L. An introduction to adverse drug reporting system in different countries. Int $\mathbf{J}$ Pharm Prac. 2005;13(1):91-100.

9. WHO Adverse Reaction Terminology. Available at : https://www.who.int/hiv/topics/pharmacovigilance/2 _who_art.pdf.

10. Naranjo CA, Busto U, Sellers EM, Sandor P, Ruiz I, Roberts EA, et al. A method for estimating the probability of adverse drug reactions. Clin Pharmacol Ther. 1981;30(2):239-45.

11. Rawlins MD, Thompson JW. Mechanisms of adverse drug reactions. In: Davies DM, eds. Textbook of adverse drug reactions. Oxford: Oxford University Press; 1991:18-45.

12. Hartwig SC, Seigel J. Preventability and severity assessment in reporting adverse drug reactions. Am J Health Syst Pharm. 1992;49(9):2229-32.

13. Schumock GT, Thornton JP. Focusing on the preventability of adverse drug reactions. Hosp Pharm. 1992;27(6):538.

14. Hurwitz N. Admissions to hospital due to drugs. Brit Med J. 1969;1(5643):539-40.

15. De Vries EN, Ramrattan MA, Smorenburg SM, Gouma DJ, Boermeester A. The incidence and nature of in-hospital adverse events: a systematic review. Qual Saf Health Care. 2008;17(3):216-23.
16. Moore N, Lecointre D, Noblet C, Mabille M. Frequency and cost of serious adverse drug reactions in a department of general medicine. Brit $\mathrm{J}$ Clin Pharmacol. 1998;45(3):301-8.

17. Saravanan SS, Kavitha P, Ponnuswamy TK. Patterns of adverse drug reactions in the medical intensive care unit of an Indian tertiary care hospital. Int J Pharm Biol Arch. 2014;5(3):64-8.

18. Sutradhar SD and Roy D. A cross-sectional study of patterns of adverse drug reactions reported in the department of pharmacology of a tertiary care teaching hospital in North East India. Int J Comprehensive Adv Pharmacol. 2017;2(1):33-5.

19. Naranjo CA, Busto U, Sellers EM, Sandor P, Ruiz I, Roberts EA, et al. A method for estimating the probability of adverse drug reactions. Clin Pharmacol Ther. 1981;30(2):239-45.

20. Goyal YN, Singh A, Bhansali NB, Jiyo C, Mistry RA, Joshi ND. Pattern of adverse drug reactions in a tertiary care hospital. J Pharmcovig Drug Safety. 2011;8(1):19-24.

21. Adhikari A, Indu R, Ray M, Bhattacharya S, Biswas $\mathrm{R}$, Das AK. Knowledge, attitude and perception of physicians towards adverse drug reaction (ADR) reporting: a pharmacovigilance study. Int J Adv Med. 2017 Nov;4(6):1685.

22. Behera SK, Rath B, Biswal SB and Mohapatra S. Pattern of adverse drug reactions in a tertiary care hospital in Western Odisha. Int J Pharm Sci Res. 2018;9(6):2471-7.

23. Rademaker M. Do women have more adverse drug reactions? Am J Clin Dermatol. 2001;2(6):349-51.

24. Kathiria JM, Sattigeri BM, Desai PM, Patel SP. A study of adverse drug reactions in patients admitted to intensive care unit of a tertiary care teaching rural hospita. Int J Pharm Pharm Sci. 2013;5(1):160-3.

25. Vora MB, Trivedi HR, Shah BK, Tripathi CB. Adverse drug reactions in inpatients of internal medicine wards at a tertiary care hospital: a prospective cohort study. J Pharmacol Pharmacother. 2011;2(1):21.

26. Rodriguez-Pena R, Antunez C, Martin E, BlancaLopez N, Mayorga C, Torres MJ. Allergic reactions to beta-lactams. Expert Opin Drug Saf . 2006;5(1):31-48.

27. Raut A, Pawar A, Pankaj M, Srivastava P, Mishra A. Clinical pattern and severity of cutaneous adverse drug reactions. Int J Pharm Sci. 2013;5(2):612-6.

28. Gor AP, Desai SV. Adverse drug reaction in the inpatients of medicine department of a rural tertiary care teaching hospital and influence of Pharmacovigilance in reporting adverse drug reactions. Ind J Pharmacol. 2008;40:210-6.

29. Karthikeyan M. A prospective observational study of medication errors in general medicine department in a tertiary care hospital. Drug Metab Drug Interact. 2013;28(1):13-21.

30. Gupta A, Kaur A, Shukla P and Chhabra H: Adverse drug reactions pattern in a tertiary level teaching hospital: a retrospective study. IJOPP. 2017;10:27-31. 
31. Shamna M, Dilip C, Ajmal M, Linu Mohan P, Shinu $\mathrm{C}$, Jafer $\mathrm{CP}$, et al. A prospective study on Adverse Drug Reactions of antibiotics in a tertiary care hospital. Saudi Pharm J. 2014;22(4):303-8.

32. Arulmani R, Rajendran SD, Suresh B. Adverse drug reaction monitoring in a secondary care hospital in South India. Brit J Clin Pharmacol. 2008;65(2):210-6.

33. Uchit GP, Shrivastava MP, Badar VA, Navale SB, Mayabhate MM. Adverse drug reactions to antimicrobial agents in a tertiary care hospital in Nagpur. J Ind Med Assoc. 2012;110:224-7.

34. Chawla S, Kalra BS, Dharmshaktu P, Sahni P. Adverse drug reaction monitoring in a tertiary care teaching hospital. J Pharmacol Pharmacother. 2011;2(3):196-8.
35. Lihite RJ, Lahkar M, Das S, Hazarika D, Kotni M, Maqbool M, Phukan S: a study on adverse drug reactions in a tertiary care hospital of Northeast India. AJM. 2017;53:151-6.

36. Mandavi, Dcruz S, Sachdev A, Tiwari P. Adverse drug reactions and their risk factors among Indian ambulatory elderly patients. Ind J Med Res. 2012;136:404-10.

Cite this article as: Kumar PK. Patterns of adverse drug reactions: a study in a tertiary care. Int J Basic Clin Pharmacol 2019;8:1497-1502. 